University of Nebraska - Lincoln

DigitalCommons@University of Nebraska - Lincoln

Faculty Papers and Publications in Animal

Science

Animal Science Department

$5-13-1997$

Evidence for Quantitative Trait Loci Affecting Ovulation Rate in

Pigs

Thomas A. Rathje

University of Nebraska-Lincoln, trathje2@unl.edu

G. A. Rohrer

USDA-ARS, gary.rohrer@ars.usda.gov

R. K. Johnson

University of Nebraska-Lincoln, rjohnson5@unl.edu

Follow this and additional works at: https://digitalcommons.unl.edu/animalscifacpub

Part of the Animal Sciences Commons

Rathje, Thomas A.; Rohrer, G. A.; and Johnson, R. K., "Evidence for Quantitative Trait Loci Affecting Ovulation Rate in Pigs" (1997). Faculty Papers and Publications in Animal Science. 95.

https://digitalcommons.unl.edu/animalscifacpub/95

This Article is brought to you for free and open access by the Animal Science Department at DigitalCommons@University of Nebraska - Lincoln. It has been accepted for inclusion in Faculty Papers and Publications in Animal Science by an authorized administrator of DigitalCommons@University of Nebraska - Lincoln. 


\title{
Evidence for Quantitative Trait Loci Affecting Ovulation Rate in Pigs ${ }^{1}$
}

\author{
T. A. Rathje*, G. A. Rohrert, and R. K. J ohnson*,2 \\ *Department of Animal Science, University of Nebraska, Lincoln 68583-0908 and \\ tUSDA Agricultural Research Service Roman L. Hruska U.S. \\ Meat Animal Research Center, Clay Center, NE 68933-0166
}

\begin{abstract}
Fifty-five microsatellite markers were scored in an $F_{2}$ population of pigs ( $n=114$ females) developed at the University of Nebraska. The population was produced by crossing a line previously selected for 10 generations using an index of ovulation rate and embryonal survival and a line selected at random. The lines were from a common base population and differed by 6.7 ovulations and 3.1 fetuses at $50 \mathrm{~d}$ of gestation. Ovulation rate and number of fully formed and mummified pigs were recorded for each female. Data were analyzed with regression models that included random animal effects. Likelihood-ratio tests were used to test for quantitative trait loci (QTL) effects by deviating the log-likelihood for the
\end{abstract}

full model that included additive and dominance QTL effects from the log-likelihood for the reduced model that did not contain QTL effects. A QTL for ovulation rate was found on chromosome $8(P<.001)$ with an additive effect of 3.07 ovulations. Other evidence of potential QTL affecting ovulation rate was found on chromosomes 4 ( $P<.10), 13$, and 15 ( $P<.05)$. Effects on chromosomes 4,13 , and 15 were not significant for an experiment-wise threshold value of $P<.001$. No significant QTL for litter size or number of mummified pigs were found. Additional data are needed to confirm the location and the effect of QTL found for ovulation rate before markers associated with them can be used in marker-assisted selection.

Key Words: Genetic Markers, Pigs, Ovulation Rate, Litter Size

J. Anim. Sci. 1997. 75:1486-1494

\section{Introduction}

Several traits, including ovulation rate, fetal survival, uterine capacity, and direct selection for litter size, have been considered as selection criteria to improve litter size in pigs. Leymaster and J ohnson (1994) concluded that selection for ovulation rate and uterine capacity (litter size) will produce the greatest response in litter size.

Quantitative selection methods involve selecting on predicted breeding value for these traits. Techniques in molecular biology can now be used to identify individual alleles with desirable effects on reproductive traits and to directly select for these alleles. Information on genotypes for marker alleles linked to these loci can be included in marker-assisted selection programs.

\footnotetext{
${ }^{1}$ Published as paper No. 11572, journal series, Nebraska Agric. Res. Div. The authors thank D. L. Hamernik for her help in developing certain laboratory procedures used in this research and C. Haley for providing software for QTL analysis.

${ }^{2}$ To whom correspondence should be addressed: A218 Animal Science, P. O. Box 830908.

Received J une 27, 1996.

Accepted J anuary 30, 1997.
}

Rothschild et al. (1996) used populations developed from Chinese Meishan and European Large White pigs to identify a locus affecting litter size. Andersson et al. (1994) used pigs resulting from a cross between the European wild boar and Large White to identify loci affecting backfat depth, abdominal fat, and intestinal length. The objective of this study was to identify loci that contribute to differences in ovulation rate and litter size between a line selected for 10 generations on an index of ovulation rate and embryonal survival and a randomly selected control line derived from the same base population.

\section{Materials and Methods}

\section{Population}

The population of pigs sampled for this experiment was developed at the University of Nebraska Swine Research Station. Two lines were sampled. The first had undergone 10 generations of mass selection for increased ovulation rate and embryonal survival ( Line I). The second line had undergone 10 generations of random selection ( Line C). Each line was derived from a common base population, which was the $F_{3}$ generation of a cross between Large White and 
Landrace. At generation zero ( $\mathrm{F}_{3}$ generation), pigs were assigned randomly, within litters, to either Line $\mathrm{C}$ or Line I. After 10 generations of selection, females from Line I had 6.7 more corpus lutea and 3.1 more fetuses at $50 \mathrm{~d}$ of gestation than females from Line $C$ (Casey et al., 1994). A complete description of the design and results of the selection experiment following five generations of selection are found in Neal et al. (1989).

An $F_{2}$ mating design was used to develop the resource population for the gene-mapping study described in this paper. The grandparents were a selected sample of animals from each line in generation 10. From Line I, females that had the greatest index for ovulation rate and embryonal survival were selected $(n=12)$. From Line $C$, females that had the least index were selected $(n=14)$. Males were sampled using the same criterion, but selection decisions were based on the index value of their dam. Sampling grandparents in this manner placed greater emphasis on differences in ovulation rate because of the effect of extremely large values for ovulation rate on the index. The weighting for ovulation rate in the index was twice that of embryonal survival. Four males from Line $C$ and five from Line I were sampled. The lines were then reciprocally crossed to produce the $\mathrm{F}_{1}$ generation by mating males from Line $\mathrm{I}$ to females from Line $C$ and males of Line $C$ to females of Line $I$. Fifty $F_{1}$ females were selected at random with at least one female retained from each full-sib family. Ten $F_{1}$ males were selected randomly with at least one male selected from each half-sib family.

Three replicates of $F_{2}$ progeny were produced. Fulland half-sib matings were not used, otherwise random matings among $F_{1}$ parents were used to produce the first and second replicates. The results presented in this paper include data only from replicate one $(\mathrm{n}=$ $114 \mathrm{~F}_{2}$ females), which represents data collected to date.

\section{Measurement of Traits}

Females of the $F_{2}$ generation were mated to crossbred boars from a Duroc- Hampshire-Yorkshire rotation crossing system. At parturition, the numbers of fully formed and mummified pigs were recorded. Pigs were weaned at approximately $12 \mathrm{~d}$ of age, and the $F_{2}$ females were monitored daily for signs of estrus. Between 7 and $14 \mathrm{~d}$ following estrus, the $F_{2}$ females were slaughtered and reproductive tracts were recovered. The number of corpora lutea present on each ovary was recorded and assumed to represent the ovulation rate of that female for the first postweaning estrus. Ovulation rate and numbers of fully formed and mummified pigs were analyzed.

\section{Genotyping}

The development of the linkage map for the pigs (Ellegren et al., 1994; Rohrer et al., 1994) increased the availability of microsatellite markers for quantitative trait loci (QTL) mapping experiments. The linkage map devel oped at the USDA Roman L. Hruska Meat Animal Research Center, Clay Center, NE (MARC; Rohrer et al., 1994), was used to select microsatellite markers that were located at approximately 30-cM intervals along each chromosome. The MARC database (Keele et al., 1994) was screened for informative markers (i.e., those that were heterozygous in the male parents of the MARC reference population). The males used in the MARC experiment were of similar genetic background (Landrace, Large White, Chester White, and Yorkshire composite) to the animals in the resource population used in this experiment. Markers that were informative in the MARC sires were scored for the grandparent sires ( $n$ = 9) used in this experiment. Markers for which multiple alleles existed were used. Approximately $85 \%$ of the markers tested were informative in the grandparent sires. Fifty-five markers were scored in all animals in the grandparent, $F_{1}$ and $F_{2}$ populations and used in the final analysis (Table 1 ). No markers assigned to chromosomes 2, 17, and 18 were used.

Three attempts at scoring difficult markers were made. If marker genotypes could not be resolved following three attempts, these markers were discarded and another informative marker in the same region was added to the analysis. Only one marker was scored on each of chromosomes 2 and 17. These markers were not used because an interval analysis could not be performed. Chromosome 18 was not included in analyses because at the time of the study definite assignment of markers to chromosome 18 was not complete (Rohrer et al., 1994).

An entire half-sib family of 13 animals was discarded from the initial data set $\left(n=127 F_{2}\right.$ females), resulting in $114 \mathrm{~F}_{2}$ females in the final data set. The genotypes within this family were inconsistent with the sire's genotype for most of the markers scored. No error in data recording or in the mating record was found to explain this discrepancy. Further DNA analysis is necessary to determine the sire of this family.

Protocols described for scoring genetic markers were based on Rohrer et al. (1994). The DNA used for genotyping was obtained from samples of either whole blood, liver, or tail tissue. Tissue was digested with proteinase K, and DNA was extracted with phenol/ chloroform and precipitated with alcohol.

The polymerase chain reaction was performed using the MJ Research thermal controller (MJ Research, USA). Approximately $12.5 \mathrm{ng}$ of DNA was plated on 96-well, U-shaped microtiter plates. Ten microliter reactions using $20 \mathrm{pmol}$ of each primer, $1.5 \mathrm{mM}$ $\mathrm{MgCl}_{2}, .45$ units Taq DNA polymerase, and $30 \mathrm{mM}$ each of dCTP, dTTP, and dGTP were completed. The concentration of dATP was reduced to $15 \mathrm{mM}$ and .1 $\mathrm{mCi}$ of $\left[\alpha^{-32 P}\right] \mathrm{dATP}$ was included in the reaction. Reactions were heated to $92^{\circ} \mathrm{C}$ for 2 min followed by 
Table 1. Microsatellite markers used in the Nebraska resource population for replicate 1

\begin{tabular}{|c|c|c|}
\hline $\begin{array}{l}\text { Chromosome and } \\
\text { marker }^{a}\end{array}$ & Position ${ }^{b}$ & Informativityc \\
\hline \multicolumn{3}{|l|}{1} \\
\hline SW64 & 0 & .3248 \\
\hline SW952 & 36.6 & .5090 \\
\hline SW307 & 62.5 & .5343 \\
\hline SW1092 & 85.8 & .5235 \\
\hline \multicolumn{3}{|l|}{3} \\
\hline SW902 & 0 & .7072 \\
\hline SW160 & 16.7 & .5600 \\
\hline SW590 & 85.1 & .2158 \\
\hline \multicolumn{3}{|l|}{4} \\
\hline SW969 & 0 & .5276 \\
\hline SW45 & 19.5 & .5618 \\
\hline SW589 & 27.3 & .5520 \\
\hline SW512 & 40.7 & .7474 \\
\hline SW445 & 72.2 & .5764 \\
\hline \multicolumn{3}{|l|}{5} \\
\hline SW2 & 0 & .4188 \\
\hline SW191 & 13.7 & .4074 \\
\hline SW1200 & 43.7 & .3609 \\
\hline SWR1112 & 68.3 & .3912 \\
\hline SW378 & 90.9 & .4478 \\
\hline \multicolumn{3}{|l|}{6} \\
\hline SW973 & 0 & .3649 \\
\hline SW1057 & 41.7 & .3629 \\
\hline SW280 & 129.7 & .3434 \\
\hline SW824 & 163.9 & .3434 \\
\hline \multicolumn{3}{|l|}{7} \\
\hline S0025 & 0 & .4892 \\
\hline SW263 & 73.3 & .2633 \\
\hline SW632 & 96.0 & .3493 \\
\hline \multicolumn{3}{|l|}{8} \\
\hline SW905 & 0 & .3888 \\
\hline SW205 & 59.1 & .4769 \\
\hline SW790 & 108.0 & .2462 \\
\hline \multicolumn{3}{|l|}{9} \\
\hline SW511 & 0 & .5748 \\
\hline SW727 & 7.3 & .5047 \\
\hline SW749 & 72.8 & .0784 \\
\hline \multicolumn{3}{|l|}{10} \\
\hline SWR136 & 0 & .4587 \\
\hline SW497 & 36.4 & .4898 \\
\hline SW951 & 72.9 & .4330 \\
\hline \multicolumn{3}{|l|}{11} \\
\hline SW151 & 0 & .5281 \\
\hline SW435 & 23.5 & .6237 \\
\hline SW13 & 45.1 & .5420 \\
\hline SW1135 & 60.7 & .5078 \\
\hline \multicolumn{3}{|l|}{12} \\
\hline SW957 & 0 & .3582 \\
\hline SW874 & 35.1 & .6211 \\
\hline SWR1021 & 76.8 & .5150 \\
\hline \multicolumn{3}{|l|}{13} \\
\hline SW935 & 0 & .2674 \\
\hline SW937 & 35.7 & .4113 \\
\hline SW873 & 61.4 & .4824 \\
\hline SW1030 & 85.6 & .4657 \\
\hline SW38 & 119.9 & .4499 \\
\hline
\end{tabular}

Table 1 (continued). Microsatellite markers used in the Nebraska resource population for replicate 1

\begin{tabular}{lcc}
\hline \hline $\begin{array}{l}\text { Chromosome and } \\
\text { marker }^{\mathrm{a}}\end{array}$ & Position $^{\mathrm{b}}$ & Informativity \\
\hline 14 & 0 & .6883 \\
SW1027 & 29.2 & .5467 \\
SWR84 & 71.4 & .6337 \\
SW761 & & \\
15 & 0 & .7444 \\
SW919 & 32.4 & .4805 \\
SW964 & 60.9 & .5372 \\
SW936 & & \\
16 & 0 & .4539 \\
SW813 & 62.5 & .4228 \\
SW81 & & \\
X & 0 & .2710 \\
SW949 & 64.5 & .4409 \\
SW707
\end{tabular}

aMarker names correspond to the linkage map described by Rohrer et al. (1994).

${ }^{b}$ Map units are in Kosambi centimorgans.

CProportion of chromosomes in $\mathrm{F}_{2}$ females for which line-origin combinations could be computed Haley et al. (1994).

30 cycles of $30 \mathrm{~s}$ at $94^{\circ} \mathrm{C}, 30 \mathrm{~s}$ at 58, or $60^{\circ} \mathrm{C}$ and $30 \mathrm{~s}$ at $72^{\circ} \mathrm{C}$, and finally $5 \mathrm{~min}$ at $72^{\circ} \mathrm{C}$.

Following amplification, an equal volume of loading dye was added to each reaction mix and 3 to $5 \mu \mathrm{L}$ was loaded onto a $6 \%$ denaturing polyacrylamide gel and electrophoresed for approximately $3 \mathrm{~h}$ at $70 \mathrm{~W}$. The gel was then blotted and the marker genotype observed with autoradiography.

Genotypes for marker alleles were scored by a single technician. At a later date, the same technician blindly scored the data again to verify correspondence with the previously recorded marker data. Errors in initial scoring were detected in approximately $3 \%$ of the genotypes for the complete set of animals.

\section{Statistical Analysis}

An analysis of linkage was done with CRIMAP version 2.4 (Green et al., 1990). Markers were analyzed in linkage groups corresponding to the linkage groups previously determined by Rohrer et al. (1994). The CHROMPIC option of CRIMAP was used to identify potential double-crossovers. Marker data that contributed to the double-crossover were scored again and scores were compared to previous ones to verify accuracy. If no scoring errors were detected, the data were retained for further analysis. Sex-averaged recombination rates were computed, except for Xlinked inheritance, and used in the following analysis.

The method and programs described by Haley et al. (1994) were used to compute the probability of an $F_{2}$ individual inheriting an allele from either Line $C$ or Line I for a QTL at a given position in the genome. This method requires the assumption that each line be 
fixed for alternative QTL if the estimate of additive and dominance effects for a QTL are to be interpreted as the effect of a single QTL allele. If this assumption is not made, the estimate of additive and dominance effects will be a function of the difference in allele frequency between the selected and control lines.

In the method of Haley et al. (1994), the two populations under investigation are arbitrarily assigned a line designation. The Index line was assigned the Line 1 designation and the Control line, the Line 2 designation. The conditional probabilities for the lineorigin of a QTL genotype given the marker data were then computed. The coefficient for the additive effect was computed as the probability of both alleles being from Line 2 subtracted from the probability of both alleles being from Line 1 . The coefficient for the dominance effect was the probability of one allele originating from Line 1 and the opposite allele originating from Line 2. Regression of phenotype on these coefficients results in an estimate of the additive effect defined as the deviation of the homozygote from the mean of the homozygotes ( $\mathrm{Fal}$ coner, 1989). An additive effect with a negative estimate is explained as individuals receiving both alleles from Line 2 having a greater mean than the mean of the homozygotes. A negative dominance effect is explained as individuals receiving an allele from each line having a lesser mean than the mean of the homozygotes.

The method described by Haley et al. (1994) was modified to include use of an animal model to account for covariance among relatives and used to analyze the data. Kennedy et al. (1992) demonstrated that biased results for the test statistic occur when correlations among observations are not in the model.

To compute QTL effects, phenotypic variance for each trait in the $\mathrm{F}_{2}$ female data was estimated and multiplied by heritability to obtain an estimate of additive genetic variance. The heritabilities and variances used were estimated from data of the selection experiment and are presented in Table 2 . The data were then fitted to an animal model without any covariates for QTL effect, using the MTDFREML programs described by Boldman et al. (1995). Additive genetic variance was held constant and a solution for error variance was obtained iteratively. The error variance and log-likelihood values were considered to be the values for the null hypothesis $\left(\mathrm{H}_{0}\right)$ of no QTL effect. The additive (a) and dominance (d) coefficients were then included in the model as covariates and the error variance and log-likelihood value were estimated iteratively for each 1-CM change in position along the chromosome. Each change in position involves altering the probability of a line-origin conditional upon the distance between the position being considered and flanking markers. This model described the alternative hypothesis $\left(\mathrm{H}_{\mathrm{a}}\right)$ of a QTL effect different from zero. By fitting line-origin probabilities as covariates for all possible pairs of QTL
Table 2. Heritability and variance components used for analysis of phenotypic data

\begin{tabular}{lccc}
\hline \hline Trait & Heritability & $\begin{array}{c}\text { Phenotypic } \\
\text { variance }\end{array}$ & $\begin{array}{c}\text { Genetic } \\
\text { variance }\end{array}$ \\
\hline Ovulation rate & .25 & 22.43 & 5.6 \\
Fully formed pigs & .12 & 6.42 & .77 \\
Mummified pigs & .05 & .624 & .03 \\
\hline
\end{tabular}

position along a linkage group, the model describes multiple QTL within linkage groups (Haley et al., 1994).

The likelihood-ratio statistic was calculated by deviating the log-likelihood value for the $\mathrm{H}_{\mathrm{a}}$ from the log-likelihood for the $\mathrm{H}_{\mathrm{O}}$. This results in a test of the hypothesis of $\mathrm{H}_{\mathrm{o}}$ vs $\mathrm{H}_{\mathrm{a}}$. Dobson (1990) demonstrated this method as follows:

$$
\begin{gathered}
D=D_{0}-D_{1}=2\left[I\left(b_{\max } ; y\right)-I\left(b_{0} ; y\right)\right]- \\
2\left[I\left(b_{\max } ; y\right)-I\left(b_{1} ; y\right)\right]=2\left[I\left(b_{1} ; y\right)-I\left(b_{0} ; y\right)\right]
\end{gathered}
$$

where $D$ is the deviance, or difference in the loglikelihood values, I $\left(b_{\text {max }} ; y\right)$ is the log-likelihood for the "maximal" model with $\mathrm{N}$ parameters where $\mathrm{N}$ corresponds to the total number of observations, and $\mathrm{I}\left(\mathrm{b}_{1} ; \mathrm{y}\right)$ and I $\left(\mathrm{b}_{0} ; \mathrm{y}\right)$ are the full (including effect of the marker) and reduced (ignoring any marker) model log-likelihood values, respectively.

The log-likelihood for the animal model is calculated in the MTDFREML programs (Boldman et al., 1995) as $L=-.5$ [constant $+\log |R|+\log |G|+\log |C|$ $+y^{\prime} P y$, where, $C$ is the full-rank coefficient matrix, $\mathrm{y}^{\prime} \mathrm{Py}$ is the generalized residual sum of squares, and $\mathrm{R}$ and $G$ are residual and genetic covariance matrices.

The models used to describe the hypotheses are summarized as follows:

$$
H_{o}: Y_{i j}=m+a_{i j}+e_{i j} \text { (reduced model) }
$$

and

$$
\begin{aligned}
H_{A}: Y_{i j}= & m+a_{i j}+b\left(a_{i}\right)+c\left(d_{i}\right) \\
& +e_{i j} \text { (full model) }
\end{aligned}
$$

where $Y_{i j}$ is the observation for the $j^{\text {th }}$ individual for the $i^{\text {th }}$ trait; $a_{i j}$ is the random animal effect for the $\mathrm{j}^{\text {th }}$ individual for the $i^{\text {th }}$ trait, which is $N\left(0, A \sigma_{a}^{2}\right), A$ representing the additive relationship matrix among observations; $b$ and $c$ are the calculated coefficients for the additive and dominance effects, respectively, of a QTL at a given position.

The effect of multiple tests of significance when performing interval analyses was first described by Lander and Botstein (1989). Using the sparse-map case, as described by Lander and Botstein (1989), an adjusted threshold value for tests of significance was calculated by dividing the chosen level of Type I errors by the number of intervals evaluated. In the experi- 
Table 3. Means and standard deviations for the grandparent, $F_{1}$, and $F_{2}$ populations

\begin{tabular}{|c|c|c|c|}
\hline Trait & Mean & SD & $\mathrm{n}$ \\
\hline \multicolumn{4}{|c|}{ Index line, grandparent females } \\
\hline Ovulation rate & 32.08 & 16.05 & 12 \\
\hline Fully formed pigs & 11.25 & 3.19 & 12 \\
\hline Mummified pigs & 1.58 & 1.11 & 12 \\
\hline \multicolumn{4}{|c|}{ Control line, grandparent females } \\
\hline Ovulation rate & 13.5 & 2.13 & 14 \\
\hline Fully formed Pigs & 8.64 & 2.22 & 14 \\
\hline Mummified pigs & .14 & .35 & 14 \\
\hline \multicolumn{4}{|c|}{ Index line, dams of grandparent males } \\
\hline Ovulation rate & 53.0 & - & 5 \\
\hline Fully formed pigs & 9.6 & - & 5 \\
\hline Mummified pigs & 1.8 & - & 5 \\
\hline \multicolumn{4}{|c|}{ Control line, dams of grandparent males } \\
\hline Ovulation rate & 11.25 & - & 4 \\
\hline Fully formed pigs & 7.5 & - & 4 \\
\hline Mummified pigs & & - & 4 \\
\hline Ovulation rate & 15.88 & 2.51 & 43 \\
\hline Fully formed pigs & 10.87 & 2.96 & 39 \\
\hline Mummified pigs & .51 & 1.34 & 39 \\
\hline \multicolumn{4}{|c|}{ - $F_{2}$ females, replicate 1} \\
\hline Ovulation rate ${ }^{1}$ & 17.05 & 4.43 & 129 \\
\hline Fully formed pigs & 11.26 & 2.57 & 119 \\
\hline Mummified pigs & .37 & .8 & 119 \\
\hline
\end{tabular}

${ }^{1}$ Measurement taken 7 to $14 \mathrm{~d}$ following first postweaning estrus.

ment described herein, there were 39 intervals bracketed by scored markers. The adjusted threshold was $\alpha /$ $M=.05 / 39=.001$. Using this value results in an experiment-wise Type I error rate of .04, calculated as $1-(1-.001)^{39}=.038$, provided there is independent inheritance of genetic markers. Using a value of .05 for declaration of significance results in an $86.5 \%$ probability of a false positive occurring somewhere in the genome; $1-(1-.05)^{39}=.865$. These values are more liberal than those proposed by Kruglyak and Lander (1995). However, the value of .001 used here is similar to the criteria for suggestive linkage proposed by those authors.

\section{Results and Discussion}

The means for ovulation rate and numbers of fully formed pigs and mummified pigs are presented in Table 3 for the grandparent, $F_{1}$, and $F_{2}$ populations. Estimates of QTL effects for ovulation rate are in Table 4. Corresponding plots of log-likelihood ratios are in Figures 1 to 4.

Table 1 contains estimates of the level of informativeness for each marker. The calculation for a single marker was based on the proportion of $F_{1}$ gametes for which a marker was informative (Haley et al., 1994). Values were 0 when a marker contributed no information and 1 when completely informative. The average level of informativeness was .464. Therefore, approximately one-half of the genotypes scored for $F_{2}$ females contributed to the analysis of QTL effect. This result emphasizes the need to select markers that are informative within a specific resource population for a genomic scan.

The assumptions made when using the above probability statements are that each marker, and thus marker interval, is inherited at random and that no covariances among experimental units exist. Genetic relationships among relatives caused a covariance to exist among observations in the $F_{2}$ females. However, the animal model accounts for this covariance. Genetic markers evenly spaced at an average of 30-cM intervals tend to be inherited together. Therefore, the assumption of independence is not strictly correct. Nevertheless, the threshold value of .001 provides additional protection against Type I errors. However, Type II errors increase if the experiment-wise error is used, possibly resulting in undetected QTL effects.

Haley et al. (1994) recommended simulation to determine appropriate threshold values for an analysis. However, results using simulation are highly dependent on the assumptions of the model used to produce the data; thus, this method is not empirical because the data to be analyzed for determining threshold values are not the same as the experimental data. The empirical method of Churchill and Doerge (1994) circumvents the problem associated with model assumptions by using the actual model to be used to analyze the data and permuting the data

Table 4. Summary for QTL effects found to be significant for ovulation rate

\begin{tabular}{|c|c|c|c|c|c|c|}
\hline $\begin{array}{l}\text { Chromosome } \\
\text { number }\end{array}$ & $\begin{array}{l}\text { Likelihood } \\
\text { ratio }\end{array}$ & df & $\begin{array}{c}\text { Map } \\
\text { position }\end{array}$ & $\begin{array}{l}\text { Additive } \\
\text { effect }^{a}\end{array}$ & $\begin{array}{l}\text { Dominance } \\
\text { effect }^{\mathrm{b}}\end{array}$ & $\begin{array}{c}\% \text { of } \mathrm{F}_{2} \\
\text { variance }\end{array}$ \\
\hline 4 & 6.79* & 2 & 32 & .42 & 3.29 & 5.1 \\
\hline 13 & $9.58^{* *}$ & 2 & 0 & -2.33 & -3.46 & 6.4 \\
\hline 15 & $7.64 * *$ & 2 & 51 & -.86 & -4.28 & 6.0 \\
\hline
\end{tabular}

a Homozygotes deviated from mean of homozygotes.

bHeterozygotes deviated from mean of homozygotes.

$* \mathrm{P}<.10$

$* * P<.05$

$* * * P<.001$. 


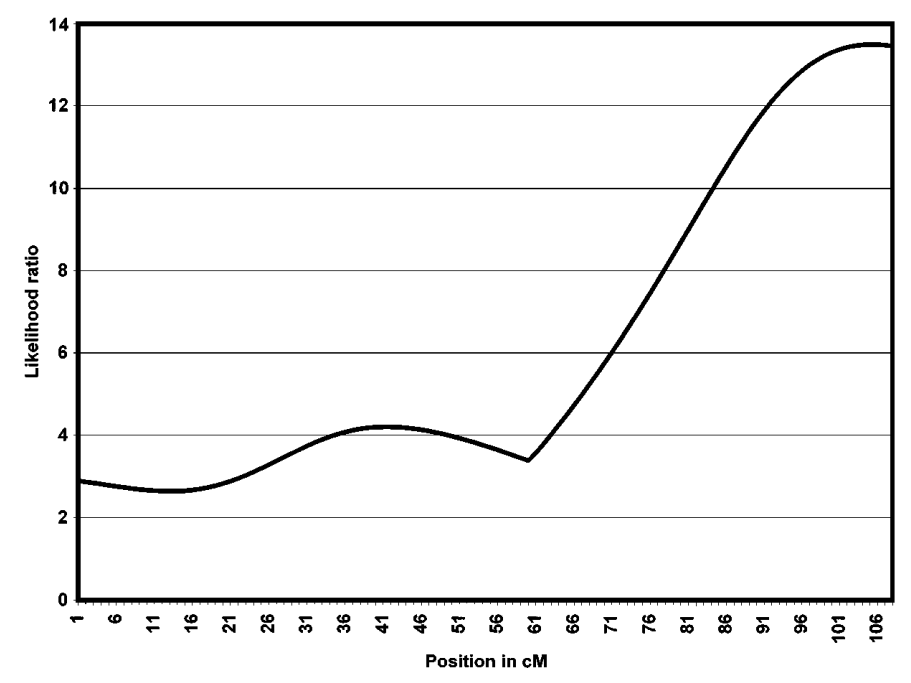

Figure 1. Likelihood ratio for ovulation rate on chromosome 8 .

among the individuals measured. This effectively breaks up marker-QTL associations and results in a distribution of the test statistic under the null hypothesis. However, the method of Churchill and Doerge (1994) is untested for situations for which the likelihood is expanded to include a random animal effect. Permuting phenotypic observations among experimental units will alter the BLUP of breeding value and render the test statistic unexchangeable under the null hypothesis.

There was strong evidence for QTL affecting ovulation rate on chromosome $8(P<.001$; Figure 1 ; Table 4). However, this QTL was not strongly related to litter size because no significant QTL were detected for the number of fully formed pigs or mummified pigs when the experiment-wise threshold of .001 for the test statistic was used. An additive effect with positive estimate is explained as individuals receiving both alleles from Line I having a greater mean than the mean of the homozygotes. A negative dominance effect is explained as individuals receiving an allele from each line having a lesser mean than the mean of the homozygotes.

On chromosome 8 (Figure 1 ), the maximumlikelihood position for a QTL affecting ovulation rate was found approximately $3 \mathrm{cM}$ proximal to marker SW790 (Rohrer et al., 1994). The estimate of the additive effect was 3.07 (Table 4). Thus, the mean ovulation rate for individuals receiving both alleles from the index line was 6.14 greater compared with females homozygous for the alternative allele. The estimate of the dominance effect was -5.35 (Table 4). The ratio of dominance $(d)$ to additive $(a)$ effect $(d / a)$ was -1.74 . An allele with complete dominance is expected to have a ratio of 1 or -1 . Therefore, the mode of gene action was dominant or overdominance. The effect of QTL alleles on chromosome 8 reduced error variance by approximately $10.9 \%$ (Table 4) when compared with a model ignoring any QTL (null hypothesis).

The estimated location was associated with marker SW790, which was the most distal marker on chromosome 8. As shown in Table 1, the proportion of informative $\mathrm{F}_{2}$ females for marker SW790 was $25 \%$. Even with the likelihood-ratio exceeding the $\mathrm{P}<.001$ threshold, Kruglyak and Lander (1995) demonstrated that chance differences in allele frequency in families of high-ovulating females may occur once per genomic scan at the suggestive linkage level of significance. Genotyping additional markers that are more informative in this region of the genome will help resolve this QTL.

The maximum-likelihood location of a putative QTL on chromosome 8 has been shown to be in a region homologous to human chromosome 4 and ovine chromosome 6 (Ellegren, 1993; Montgomery, 1993). Ovine chromosome 6 contains the Fec ${ }^{B}$ locus, which has been demonstrated to increase ovulation rate in carrier and homozygous ewes (Montgomery et al., 1992).

The estimate for dominance for the QTL on chromosome 8 was -5.35 . Heterozygous individuals had fewer corpora lutea than females that inherited both alleles from the Control line. Possibly the allele at the locus on chromosome 8 with positive effect on ovulation rate is recessive and through selection had increased in frequency.

There was evidence $(P<.05$; Table 4; Figure 2$)$ for a QTL affecting ovulation rate on chromosome 13 at a maximum-likelihood position at or near SW935. Therefore, a QTL may lie beyond this marker outside of the interval evaluated in this analysis. This QTL explained $6.4 \%$ of the error variance. The difference between Control and Index line alleles was estimated to be -2.33 and the dominance effect estimate was -3.46. A dominant or overdominant mode of gene

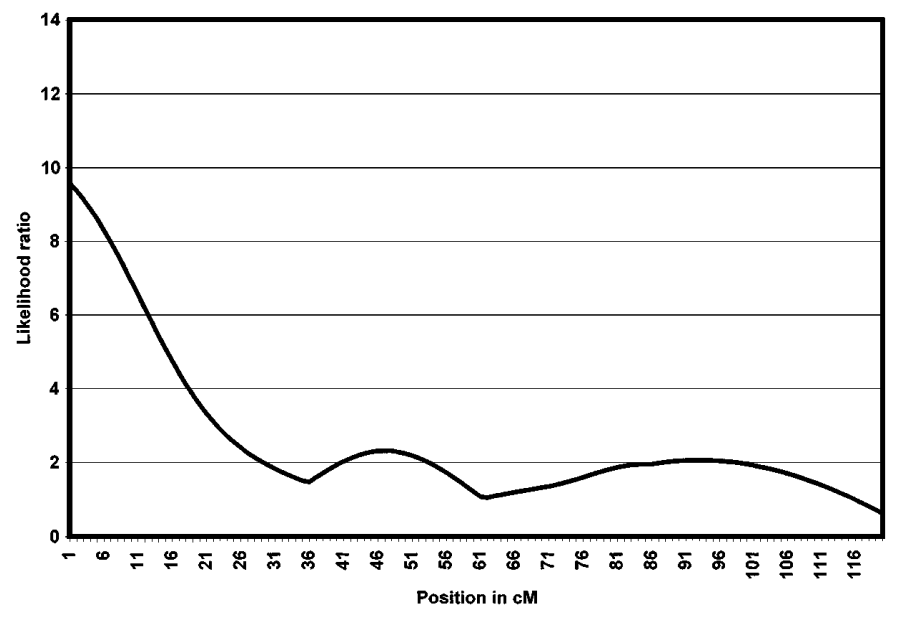

Figure 2. Likelihood ratio for ovulation rate on chromosome 13. 


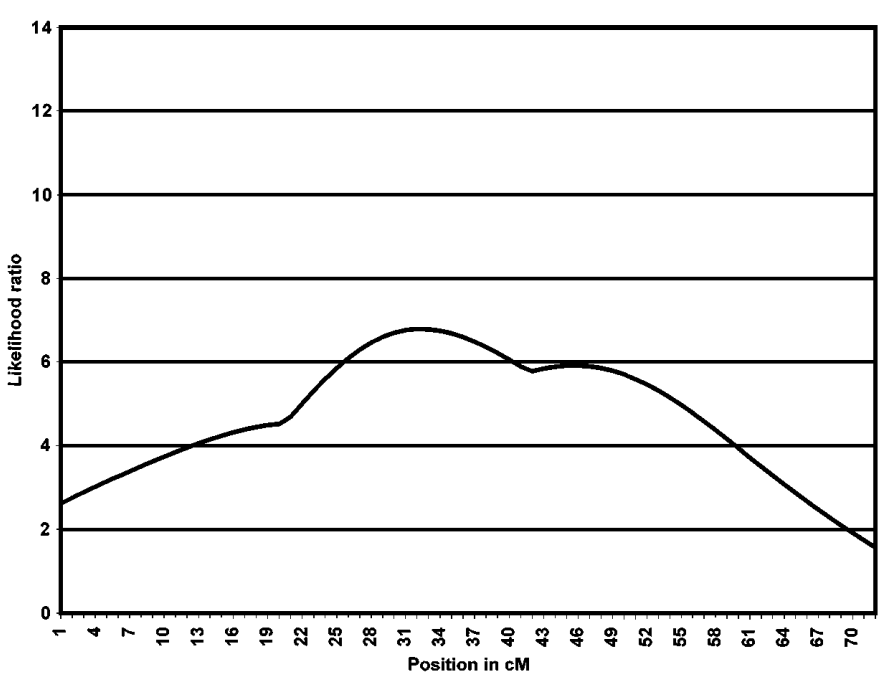

Figure 3. Likelihood ratio for ovulation rate on chromosome 4 .

action can be hypothesized from the ratio of $d / a$ (1.48). Individuals receiving both alleles from the Control line ovulated more eggs than individuals receiving both alleles from the Index line. This result is unexpected given the selection background of the population if the effect of the QTL is purely additive. However, the estimated additive and dominance effects are what would occur for overdominance. Frequency-dependent selection could explain the observed result. If the frequency of the desirable allele is low, selection for that allele will tend to eliminate the allele from the population. This occurs because most of the desirable alleles are present in the population as heterozygotes; selection will tend to eliminate heterozygotes if the dominance effect $(-3.46)$ is opposite the selection pressure.

Evidence for QTL alleles for ovulation rate on chromosomes 4 ( $\mathrm{P}<.10$; Table 4; Figure 3 ) and 15 ( $\mathrm{P}$ $<.05$; Table 4; Figure 4) was found. The additive effect of the allele on chromosome 15 was -.86 and the dominance effect was -4.28 . Control alleles tended to increase ovulation rate and heterozygotes ovulated fewer eggs than index line homozygotes. The ratio of $\mathrm{d} / \mathrm{a}$ was 4.98, which again is evidence for overdominance. The maximum-likelihood location was at map position 51, $9 \mathrm{cM}$ proximal to marker SW936. This locus explained $6.0 \%$ of the error variance for the $F_{2}$ population.

The effects associated with chromosomes 13 and 15 were similar in that Control line alleles tended to increase ovulation rate. The possibility of Type I errors is greater when the P-value of .05 is used, so results on chromosomes 13 and 15 could be false positives. Further experimentation with greater marker densities and increased numbers of experimental units is warranted for these regions of the genome.

Weaker evidence for a QTL near map position 32 on chromosome 4 ( $\mathrm{P}<.10$; Table 4; Figure 3) was found.
This location was approximately $5 \mathrm{cM}$ distal to marker SW589 and 9 cM proximal to marker SW512. The estimate of additive effect was .42. Index line homozygotes had more ovulations than Control line homozygotes. The dominance effect was 3.29 with a d/ a ratio of 7.91. Heterozygotes ovulated larger numbers of eggs than either homozygote. The P-value for this estimate was .10; therefore, there is a high probability this result is a false positive.

The models described by Haley et al. (1994) were among the first for data from outbred line crosses. However, their models do not account for individual QTL effects but actually produce estimates of differences among the average QTL in the lines composing the cross. If these lines differ widely in phenotype, the underlying assumption is that the two lines are fixed for alternative QTL alleles. Only in this case does the method described by Haley et al. (1994) accurately reflect differences in individual QTL effect. Otherwise, the additive effects estimated are some function of differences in allele frequency between lines. Nevertheless, the method of Haley et al. (1994) is the only easily applied method available for outbred line crosses and the method is well suited in early studies of populations to determine whether QTL exist for traits of interest.

A shortcoming of the models described by Haley et al. (1994) and other authors (Lander and Botstein, 1989; Martinez and Curnow, 1992; Zeng, 1994) is a failure to account for covariances among observations created by genetic relationships. Kennedy et al. (1992) demonstrated that failing to account for these covariances results in biased estimates of QTL effect. Goddard et al. (1992) proposed a method that incorporated the random animal effect and a "gametic relationship matrix"; however, no software is currently available for application of that method. For this

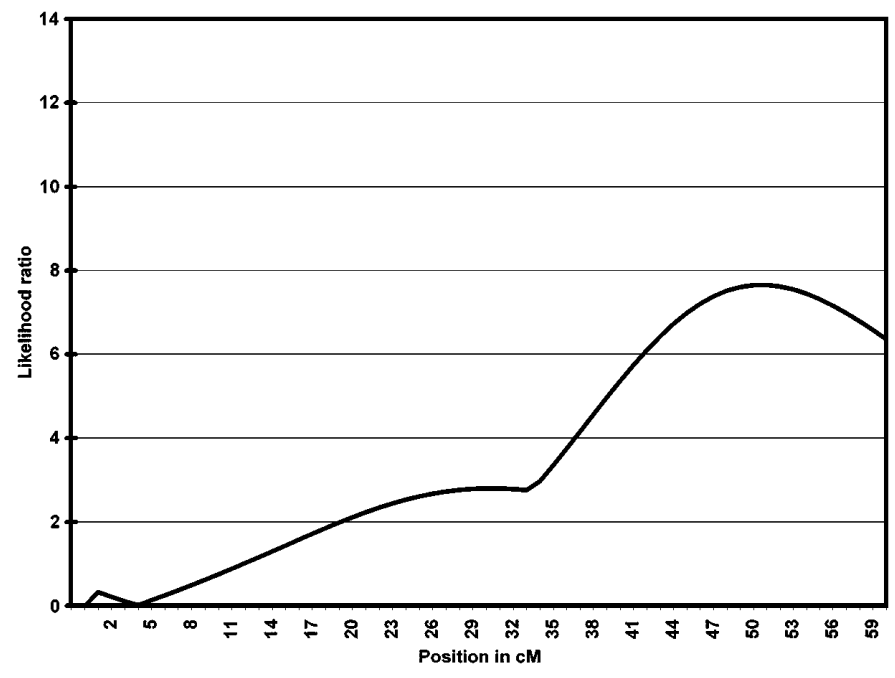

Figure 4. Likelihood ratio for ovulation rate on chromosome 15. 
study, an animal model was used to account for genetic relationships among animals, and the coefficients for the additive and dominance effects of the QTL were fitted as covariates, according to the method of Haley et al. (1994). Fitting an animal model in this way was difficult because of the small number of observations available.

The variance in the $F_{2}$ population for a given trait is, in most cases, larger than the estimate from the original parental populations. Therefore, estimates of additive genetic and error variance must be made directly from the data collected on the $F_{2}$ individuals. In most instances with QTL mapping studies, the number of $F_{2}$ individuals is less than needed for precise estimates of variance components. In this experiment, the estimate of additive genetic variance in the $F_{2}$ data was zero for ovulation rate (data not presented). Other experiments using the same parental populations (Neal et al., 1989; Casey et al., 1994) found different results. Casey et al. (1994) estimated heritability of ovulation rate at .28, similar to the estimate from Neal et al. (1989). Furthermore, response to selection was an increase of approximately 6.7 corpora lutea. Therefore, additive genetic variance must be different from zero. The method used was to estimate phenotypic variance for the $F_{2}$ population and then estimate additive genetic variance using a heritability $\left(\mathrm{h}^{2}\right)$ of .25 . A similar method was used for fully formed pigs ( $\mathrm{h}^{2}=.12$ ) and number of mummies $\left(h^{2}=.05\right)$.

Another shortcoming of the analysis was that the results estimated line differences at each locus in the genome bracketed by markers. Several haplotypes likely exist in outbreeding populations. Therefore, to apply marker-assisted selection, the effects of individual haplotypes must be estimated. The method used herein did not produce such an estimate. The estimates of additive and dominance effect are as a function of differences in allele frequency between the two lines, which was not known.

Litter size at birth is the minimum of potentially viable embryos (ovulation rate) and uterine capacity (Bennett and Leymaster, 1989). The possible QTL for ovulation rate found in this study were not strongly related to litter size because no QTL effects for litter size were found. This could be because uterine capacity and not ovulation rate is the most limiting variable in litter size in this population. If so, variation in ovulation rate would not be strongly related to litter size and QTL for ovulation rate may not affect litter size. Alternatively, the QTL for ovulation rate may affect litter size, but to a lesser degree than they affect ovulation rate because of the additional variance in litter size from uterine capacity. If so, more data are necessary for ovulation rate QTL to have significant effects on litter size. The experiment reported herein might have lacked the precision to detect ovulation rate QTL that also affected litter size.

\section{Implications}

Evidence for quantitative trait loci for ovulation rate was found on chromosomes 4, 8, 13, and 15 . Effects on chromosomes 4, 13, and 15 had threshold values that did not exceed the adjusted experimentwise value of .001. More markers and larger $F_{2}$ populations are required to verify the effects and the location of the QTL. Data were analyzed with an animal model to account for covariance among records. There is a need for further refinement and study of statistical models and methods to analyze data from QTL mapping experiments with segregating populations. Development of such models will enhance application of marker-assisted selection.

\section{Literature Cited}

Andersson, L., C. S. Haley, H. Ellegren, S. A. Knott, M. J ohansson, K. Andersson, L. Andersson-Eklund, I. Edfors-Lilja, M. Fredholm, I. Hansson, J. Hakansson, and K. Lundstrom. 1994. Genetic mapping of quantitative trait loci for growth and fatness in pigs. Science (Wash., DC) 263:1771.

Bennett, G. L., and K. A. Leymaster. 1989. Integration of ovulation rate, potential embryonic viability and uterine capacity into a model of litter size in swine. J. Anim. Sci. 67:1230.

Boldman, K. G., L. A. Kriese, L. D. Van Vleck, C. P. Van Tassell, and S. D. Kachman. 1995. A manual for the use of MTDFREML: A set of programs to obtain estimates of variances and covariances [Draft]. ARS, USDA, Washington, DC.

Casey, D., T. A. Rathje, and R. K. J ohnson. 1994. Response to ten generations of index selection for components of litter size in swine. In: Proc. 5th World Congr. Genet. Appl. Livest. Prod. 17: 315.

Churchill, G. A., and R. W. Doerge. 1994. Empirical threshold values for quantitative trait mapping. Genetics 138:963.

Dobson, A. J. 1990. Chapter 5. Inference. In: An Introduction to Generalized Linear Models. Chapman and Hall, New York.

Ellegren, H. 1993. Conserved syntony between pig chromosome 8 and human chromosome 4 but rearranged and distorted maps. Genomics 17:599.

Ellegren, H., B. P. Chowdhary, M. J ohansson, L. Marklund, M. Fredhold, I. Gustavsson, and L. Andersson. 1994. A primary linkage map of the porcine genome reveals a low rate of genetic recombination. Genetics 137:1089.

Falconer, D. S. 1989. Chapter 7: Values and Means. In: Introduction to Quantitative Genetics. p 111. Longman Scientific and Technical, Essex, U.K.

Goddard, M. E. 1992. A mixed model for analyses of data on multiple genetic markers. Theor. Appl. Genet. 83:878.

Green, P., K. Falls, and S. Crooks. 1990. Documentation for CRIMAP, Version 2.4. Washington University School of Medicine, St. Louis.

Haley, C. S., S. A. Knott, and J. M. Elsen. 1994. Mapping QTL in crosses between outbred lines using least squares. Genetics 136:1195-1207.

Keele, J . W., J . E. Wray, D. E. Behrens, G. A. Rohrer, S.L.F. Sunden, S. M. Kappes, M. D. Bishop, R. T. Stone, L. J . Alexander, and C. W. Beattie. 1994. A conceptual database model for genomic research. J. Comp. Biol. 1:65-76.

Kennedy, B. W., M. Quinton, and J A.M. van Arendonk. 1992. Estimation of effects of single genes on quantitative traits. J. Anim. Sci. 70:2000. 
Kruglyak, L., and E. S. Lander. 1995. A nonparametric approach for mapping quantitative trait loci. Genetics 139:1421-1428.

Lander, E. S., and D. Botstein. 1989. Mapping Mendelian factors underlying quantitative traits using RFLP linkage maps. Genetics 121:185.

Leymaster, K. A., and R. K. J ohnson. 1994. Second thoughts on selection for components of reproduction in swine. In: Proc. 5th World Congr. Genet. Appl. Livest. Prod. 17:307.

Martinez, O., and R. R. Curnow. 1992. Estimating the locations and the sizes of the effects of QTL using flanking markers. Theor. Appl. Genet. 85:480.

Montgomery, G. W. 1993. The ovine booroola fecundity gene (F ecB) is linked to markers from a region of human chromosome $4 \mathrm{q}$. Nat. Genet. 4:410.

Montgomery, G. W., K. P. McNatty, and G. H. Davis. 1992. Physiol- ogy and molecular genetics of mutations that increase ovulation rate in sheep. Endocr. Rev. 13:309.

Neal, S. M., R. K. J ohnson, and R. J . Kittok. 1989. Index selection for components of litter size in swine: Response to five generations of selection. J. Anim. Sci. 67:1933.

Rohrer, G. A., L. J. Alexander, J. W. Keele, T. P. Smith, and C. W. Beattie. 1994. A microsatellite linkage map of the porcine genome. Genetics 136:231.

Rothschild, M. F., C. J acobson, D. A. Vaske, C. K. Tuggle, L. Wang, T. Short, G. R. Eckardt, S. Sasaki, A. Vincent, D. McLaren, O. Southwood, H. van der Steen, A. Mileham, and G. Plastow. 1996. The estrogen receptor locus is associated with a major gene influencing litter size in pigs. Proc. Natl. Acad. Sci. USA 93:201-205.

Zeng, Z. B. 1994. Precision mapping of QTL. Genetics 136:1457. 